\title{
Reinforced glass beams; Effect of increased temperatures on the glass-to-reinforcement adhesive bond
}

\author{
Authors: \\ Christian Louter, Delft University of Technology, Faculty of Architecture, p.c.louter@tudelft.nl \\ Dieter Callewaert, Ghent University, LMO, Department of Structural Engineering \\ Jan Belis, Ghent University, LMO, Department of Structural Engineering \\ Fred Veer, Delft University of Technology, Faculty of Architecture \\ Freek Bos, Delft University of Technology, Faculty of Architecture
}

\begin{abstract}
For several years the Glass \& Transparency research group at Delft University of Technology has been working on safety concepts for glass structures and structural glass components. In contrast with common 'safety' approaches, the developed safety concepts do not rely on overdimensioning, but aim at controlled and ductile failure behaviour. Since glass itself is a brittle material, the research group focuses on the development of glass-composite concepts in which the ductility is obtained by a combined action of glass and a ductile material [1].

One of the concepts currently under investigation is the 'reinforced glass beam' concept [2]. This concept makes use of a stainless steel reinforcement, which is adhesively bonded to the edge of an annealed float glass beam. Similar to reinforced concrete this reinforcement section will act as a crack bridge, taking up the tensile forces once the glass has cracked due to unforeseen circumstances. The reinforcement section will provide redundancy to the system; the tensile forces will be taken up by the reinforcement while the compressive forces will be taken up by the uncracked compression zone. This way safe and ductile failure behaviour is obtained.

An important aspect of the reinforced glass beam concept is the adherence of the reinforcement to the glass. Since all interaction between glass and reinforcement is dependent on this adhesive bond, it has to service under all conditions. A very important condition is an increased serviceability temperature, since e.g. glass roofs are often exposed to direct sunlight radiation. The effect of increased temperatures on the adhesive bond has been investigated in cooperation with glass-researchers at Ghent University. For this research a climatic room at Ghent University has been equipped with a 4-point bending test setup. A total of thirty $1.5 \mathrm{~m}$ reinforced glass beam specimens have been stored for at least 24 hours at $60^{\circ} \mathrm{C}$, before being tested in 4-point bending at this same temperature level. Using this method, six different adhesives have been investigated. Results show the acrylic specimens performed best.
\end{abstract}

\section{INTRODUCTION}

The application of glass as a structural material in building structures is rapidly increasing. Glass is applied as structural material for e.g. floors, roofs, façade fins, columns and beams. Since glass has no plastic deformation capacity and shows brittle failure, the application of glass as a structural material requires a profound safety concept. In current building practices the safety of a structural glass beam often depends on overdimensioning. Strong (toughened) glass types are used and sacrificial outer sheets are added to the beam laminate to protect the inner layers. If one of the outer sheets fails due to an impact (e.g. vandalism) the remaining sheets will still be able 
to carry load. However, due to repeated impacts or assembly errors (most notably at the joints or supports) all layers of the beam laminate might be affected and the beam might still collapse. The developed 'reinforced glass beam' concept has been developed from a totally different perspective. Rather than adding more layers to the beam laminate to minimize the probability of a collapse, it aims at controlled and ductile failure through the addition of an adhesively bonded stainless steel reinforcement. Upon overloading the glass will crack, but crack growth will be limited due to the dissipation of fracture energy by elongation of the reinforcement. Cracks are diverted at reaching the compression zone, which will therefore remain uncracked. Since both tension (by the reinforcement) and compression (by the glass) can still be transferred, the beam will still be able to carry a reasonable load.

Current research focuses on the adhesive bond between the glass and reinforcement. The strength of an adhesive bond is, amongst other aspects, strongly dependent on temperature. In general, adhesive bonds show a reduced stiffness and strength at increased temperatures and a more brittle behaviour at decreased temperatures. Since temperatures up to $60^{\circ} \mathrm{C}$ can easily occur for sun-exposed beams applied in a glass roof structure, this condition has to be investigated for the reinforced glass beam concept.

\section{AdHESIVES}

To investigate the effect of elevated temperatures, $1.5 \mathrm{~m}$ reinforced glass beam specimens have been prepared with different adhesives, stored for at least 24 hours at $60^{\circ} \mathrm{C}$ and subsequently tested in 4 -point bending at $60^{\circ} \mathrm{C}$. The applied adhesives vary in curing time, color, strength and gap-filling properties (see table 1). The UV-curing acrylic adhesives [4] (DELO GlasBond 368, 4468 and 485; abbreviations: GB368, GB4468, GB485) provide the advantages of transparency and short curing times. However, their gap-filling capacities are limited which might endanger the structural quality of the adhesive bond due to varying thicknesses caused by dimensional inaccuracies between glass and reinforcement (see figure 1). The applied 2component epoxy [5] (Araldite 2013, abbreviation: AR2013), 2-component polyurethane [6] (Araldite 2026, abbr.: AR2026) and silicone (Dow Corning 895, abbr.: DC895) provide the advantage of large gap-filling properties (up to $5 \mathrm{~mm}$ ). Their curing times, however, are long, which increases production time. Furthermore, the epoxy and silicone are not transparent and cannot be used for glass-to-glass bonding. This limits their applicability for the production of large span segmented reinforced glass beams [2], which are developed at Delft University of Technology. Those beams are composed of several adhesively bonded glass segments and continuous stainless steel reinforcement. To facilitate the production process and to prevent any contamination, the beams are preferably fully bonded with only one (transparent) type of adhesive. Alternatively, in case of a non-transparent glass-to-reinforcement adhesive bond, the reinforcement has to be bonded to the beam laminate afterwards. This, however, increases production time, since the production process has to be split up in glass-to-glass and glass-toreinforcement bonding. 


\begin{tabular}{|l|l|l|l|l|}
\hline Adhesive & Shear strength [MPa] $*$ & Curing time & Color & Gap-filling capacity [mm] \\
\hline AR2013 (2-comp.epoxy) & 18 & $>10$ hours at 23 ${ }^{\circ} \mathrm{C}$ & grey & up to 5 \\
\hline GB368 (acrylic) & 23 (glass-alu) & $30-60$ sec. by UV & transparent & $<0,1$ \\
\hline GB485 (acrylic) & 19 (glass-alu) & $30-60$ sec. by UV & transparent & $<0,1$ \\
\hline GB4468 (acrylic) & 24 (glass-alu) & $30-60$ sec. by UV & transparent & $<0,1$ \\
\hline AR2026 (2-comp.pur) & 7 (glass-glass) & $>8$ hours at 23 ${ }^{\circ} \mathrm{C}$ & transparent & Not stated by datasheet \\
\hline DC895 (1-comp.silicone) & 1.06 (tensile strength) & $>72$ hours & black & Not stated by datasheet \\
\hline
\end{tabular}

TABLE 1 - OVERVIEW OF ADHESIVE PROPERTIES AS PROVIDED BY MANUFACTURER.

\section{METHOD}

\section{Beam specimen preparation}

For this research $1.5 \mathrm{~m}$ long reinforced glass beam specimens have been manufactured. Each specimen consists of a $1500 * 115 * 10 \mathrm{~mm}$ inner glass layer, two $1500 * 40 * 6 \mathrm{~mm}$ outer glass layers and a $10 * 10 * 1 \mathrm{~mm}$ stainless steel box section (see figure 1 ). The reinforcement is encapsulated by both outer layers which enlarges the bond area between glass and reinforcement thus enhances the transfer of forces between glass and reinforcement.

Six different adhesives have been applied for bonding the reinforcement to the glass (see table 1). Per adhesive type 5 specimens have been made. Both outer glass layers have been bonded to the inner glass layer using the same adhesive as applied for glass-to-reinforcement bonding, except for the non-transparent and/or slow-curing AR2013-, AR2026- and DC895specimens. For those specimens the outer glass layers were bonded using the GB368, which has the advantages of transparency and short curing time (30-60 sec. by UV-radiation).

For the UV-curing adhesives (GB4468, GB368 and GB485) both glass-to-glass and glass-toreinforcement bonding has been performed simultaneously. For the remaining (slow-curing and/or non-transparent) adhesives first both outer glass layers have been bonded to the inner layer. The reinforcement has been bonded afterwards and was clamped, conform the manufacturer's instructions, for 24 hours.
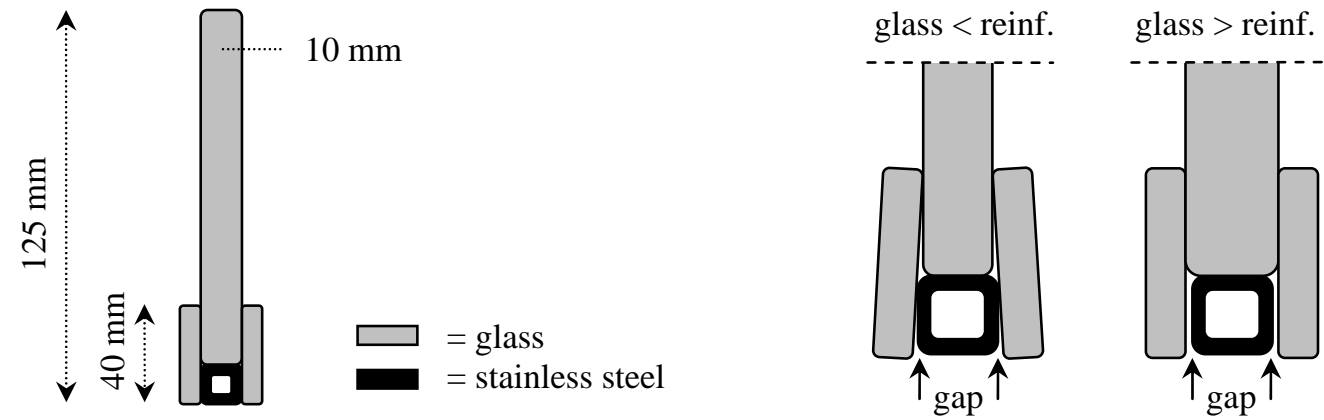

FIGURE 1 - LEFT: CROSS SECTION. RIGHT: GAPS DUE TO DIMENSIONAL INACCURACIES. 


\section{Experimental setup}

The $1.5 \mathrm{~m}$ reinforced glass beam specimens have been stored at $60^{\circ} \mathrm{C}$ in a climatic room for at least 24 hours. Subsequently the beams have been tested in 4-point bending, still at $60^{\circ} \mathrm{C}$. The climatic room has been provided with a displacement controlled 4-point bending test setup (see figure 2) in which the supports were $1400 \mathrm{~mm}$ apart and the loads were $400 \mathrm{~mm}$ apart. Lateral (anti-buckling) supports were $550 \mathrm{~mm}$ apart. The load was applied using a hydraulic jack, which was manually operated.
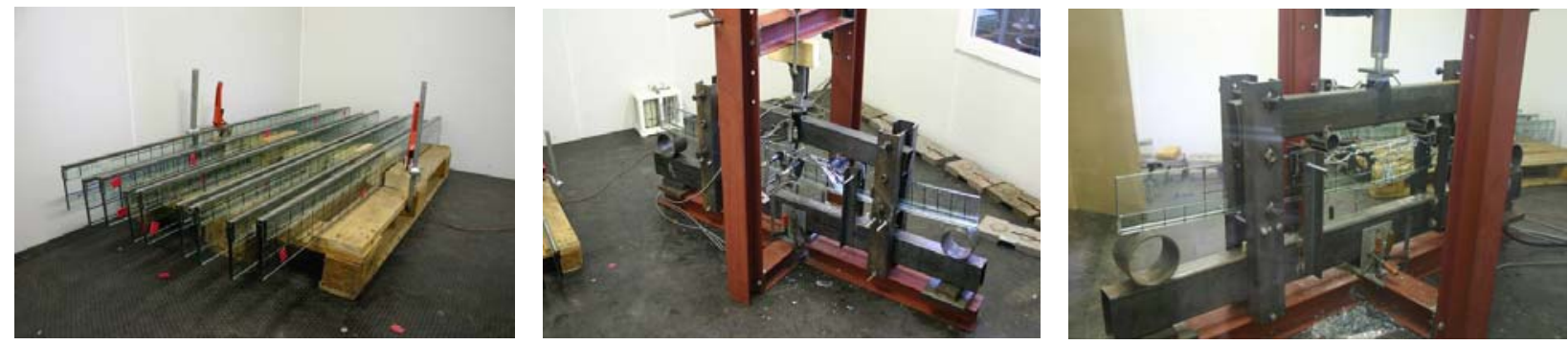

FIGURE 2 - LEFT: STORAGE OF THE BEAM SPECIMENS. MIDDLE+RIGHT: BENDING TEST SETUP.

\section{RESULTS}

The results of the tests are summarized in table 2 and will be specified per applied adhesive type.

\begin{tabular}{|c|c|c|c|c|c|c|}
\hline \multirow[t]{2}{*}{ Adhesive } & \multirow[t]{2}{*}{ Specimen } & \multicolumn{2}{|c|}{ Initial fail.load } & \multirow{2}{*}{$\frac{\text { Crack-height }}{[\mathrm{mm}]}$} & \multirow{2}{*}{$\frac{\text { Post-fail. load }}{[\mathrm{kN}]}$} & \multirow{2}{*}{$\begin{array}{c}\text { Remaining load-carrying capacity } \\
\text { [postf.load / init.fail.load x } 100 \%\end{array}$} \\
\hline & & {$[\mathrm{kN}]$} & {$[\mathrm{MPa}]$} & & & \\
\hline \multirow[t]{5}{*}{ Epoxy } & AR2013 \#01 & 7.2 & 37.2 & $100 / 125$ & 6.6 & 91 \\
\hline & AR2013 \#02 & 7.1 & 36.4 & $90 / 125$ & 6.3 & 89 \\
\hline & AR2013 \#03 & 6.7 & 34.6 & $95 / 125$ & 5.1 & 75 \\
\hline & AR2013 \#04 & 7.1 & 36.9 & $90 / 125$ & 7.9 & 111 \\
\hline & AR2013 \#05 & 7.2 & 37.3 & $100 / 125$ & 7.9 & 109 \\
\hline \multirow{5}{*}{ Acrylic } & GB368 \#01 & 8.8 & 45.6 & $95 / 125$ & 10.5 & 119 \\
\hline & GB368 \#02 & 9.3 & 47.9 & $100 / 125$ & 9.5 & 102 \\
\hline & GB368 \#03 & 7.3 & 37.9 & $90 / 125$ & 11.4 & 156 \\
\hline & GB368 \#04 & 8.1 & 41.7 & $100 / 125$ & 9.8 & 122 \\
\hline & GB368 \#05 & 7.6 & 39.1 & $90 / 125$ & 11.8 & 156 \\
\hline \multirow[t]{5}{*}{ Acrylic } & GB485 \#01 & 9.1 & 47.1 & $100 / 125$ & 6.7 & 74 \\
\hline & GB485 \#02 & 8.2 & 42.3 & $90 / 125$ & 9.5 & 116 \\
\hline & GB485 \#03 & 6.9 & 35.7 & $100 / 125$ & 10.8 & 156 \\
\hline & GB485 \#04 & 9.5 & 48.8 & $90 / 125$ & 12.4 & 131 \\
\hline & GB485 \#05 & 7.5 & 38.9 & $90 / 125$ & 12.3 & 163 \\
\hline \multirow[t]{5}{*}{ Acrylic } & GB4468 \#01 & 5.8 & 29.9 & $80 / 125$ & 10.1 & 174 \\
\hline & GB4468 \#02 & 8.2 & 42.3 & $100 / 125$ & 8.7 & 106 \\
\hline & GB4468 \#03 & 8.5 & 43.8 & $100 / 125$ & 8.1 & 96 \\
\hline & GB4468 \#04 & 7.9 & 40.9 & $90 / 125$ & 12.0 & 151 \\
\hline & GB4468 \#05 & 7.6 & 39.2 & $100 / 125$ & 10.3 & 136 \\
\hline \multirow[t]{5}{*}{ Polyurethane } & AR2026 \#01 & 6.6 & 34.0 & $100 / 125$ & 5.5 & 83 \\
\hline & AR2026 \#02 & 6.6 & 34.1 & 100/125 & 4.5 & 68 \\
\hline & AR2026 \#03 & 8.2 & 42.4 & $100 / 125$ & 4.9 & 60 \\
\hline & AR2026 \#04 & 8.4 & 43.4 & $100 / 125$ & 5.4 & 65 \\
\hline & AR2026 \#05 & 8.4 & 43.6 & 100/125 & 5.0 & 59 \\
\hline \multirow[t]{5}{*}{ Silicone } & DC895 \#01 & 9.0 & 46.3 & $125 / 125$ full & 0 & 0 \\
\hline & DC895 \#02 & 8.4 & 43.5 & $125 / 125$ full & 0 & 0 \\
\hline & DC895 \#03 & 7.0 & 36.3 & $125 / 125$ full & 0 & 0 \\
\hline & DC895 \#04 & 5.2 & 27.0 & 75/125 & 4.7 & 90 \\
\hline & DC895 \#05 & 8.3 & 42.9 & $125 / 125$ full & 0 & 0 \\
\hline
\end{tabular}

TABLE 2: OVERVIEW OF THE RESULTS OF THE BENDING TESTS AT $60^{\circ} \mathrm{C}$. 


\section{Epoxy specimens}

Figure 3 shows the stress-displacement diagram of the epoxy-specimens. After an initial linear elastic response the epoxy-specimens showed a V-shaped initial crack (stage I) with a height of about 90-100 mm, leaving a compression zone of 25-35 mm uncracked. As loading was continued the initial crack started to propagate horizontally (stage II) until at a certain point in the loading procedure the reinforcement started to debond and horizontal cracks started to occur in the previously uncracked compression zone (stage III). At this point the beam specimens lost there bending stiffness (see stage III in figure 3). Although the reinforcement was debonded and started to slip, the beam specimens still showed a remaining load-carrying capacity of 75-91\%.
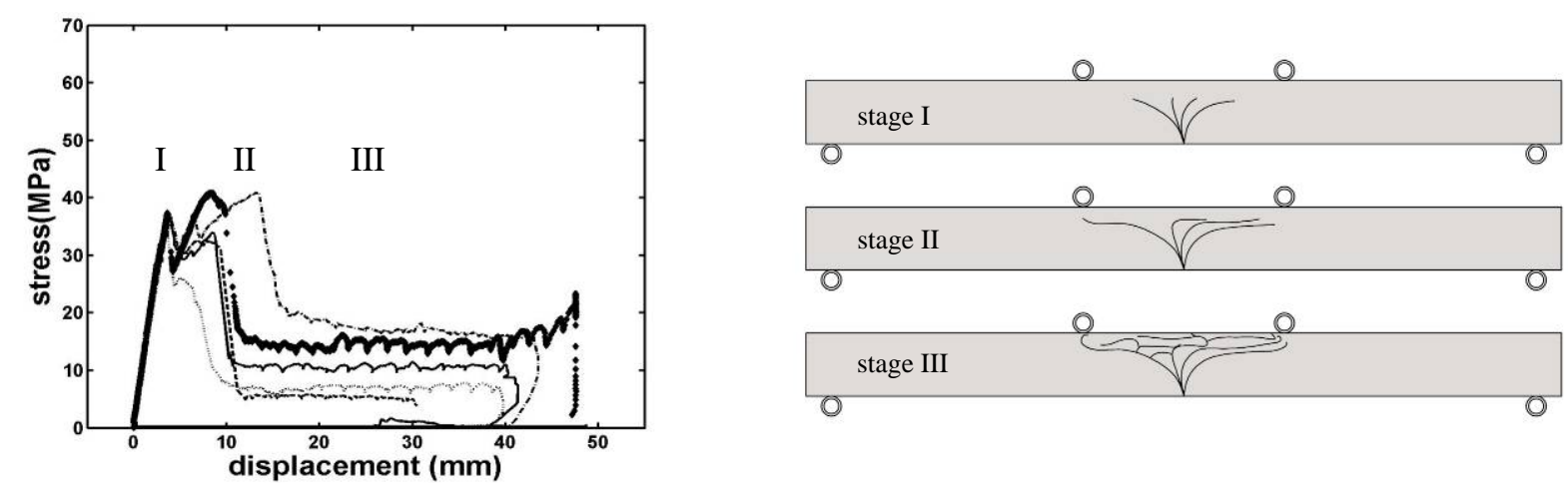

FIGURE 3 - DIAGRAM AND CRACKING SEQUENCE (STAGE I-III) OF EPOXY (AR2013) SPECIMENS.

\section{Acrylic specimens}

Although three different acrylic adhesives (GB368, GB485 and GB4485) have been tested, the acrylic specimens all showed similar failure behaviour (see figures 4, 5 and 6). The acrylicspecimens showed an initial V-shaped crack (stage I) with a height of about 90-100 mm, leaving a compression zone of 25-35 mm uncracked. As loading was continued, typically a second Vshaped crack (stage II) occurred for the GB368 and GB4468 specimens. Gradually the existing cracks started to propagate horizontally and new horizontal cracks occurred in the compression zone (stage III+IV). The specimens showed a remaining load-carrying capacity of 74-174\%. Final failure occurred due to full and brittle debonding of the reinforcement.
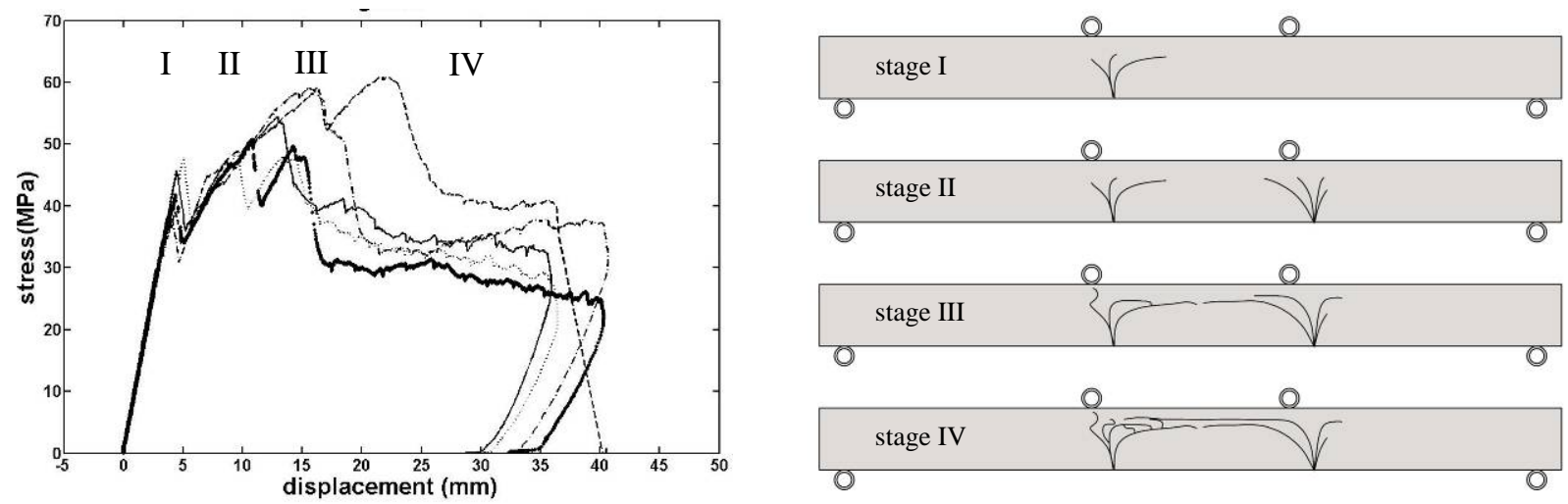

FIGURE 4 - DIAGRAM AND CRACKING SEQUENCE (STAGE 1-4) OF ACRYLIC (GB368) SPECIMENS. 

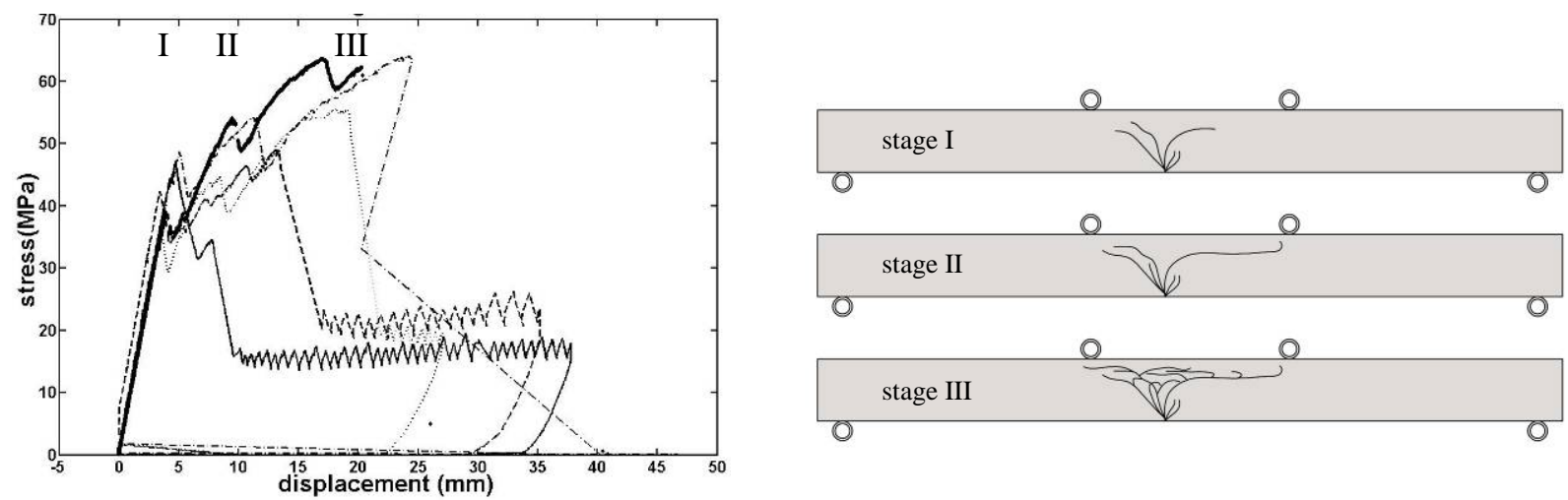

FIGURE 5 - DIAGRAM AND CRACKING SEQUENCE (STAGE I-III) OF ACRYLIC (GB485) SPECIMENS.
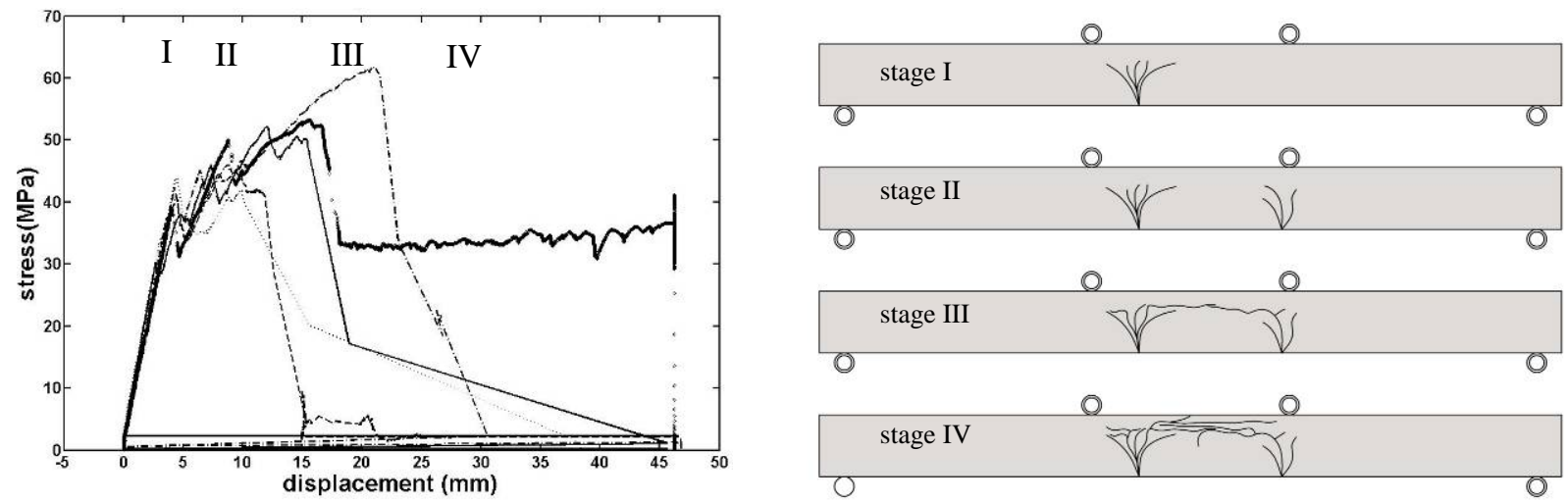

FIGURE 6 - DIAGRAM AND CRACKING SEQUENCE (STAGE I-IV) OF ACRYLIC (GB4468) SPECIMENS

\section{Polyurethane specimens}

The polyurethane specimens showed a large initial V-shaped crack with widely extended horizontal branches (see figure 7, stage I). At initial failure the reinforcement instantly debonded and as loading was continued the reinforcement section started to slip. The load did not reach the initial failure load anymore and the remaining load-carrying capacity was limited to 59-83\%.
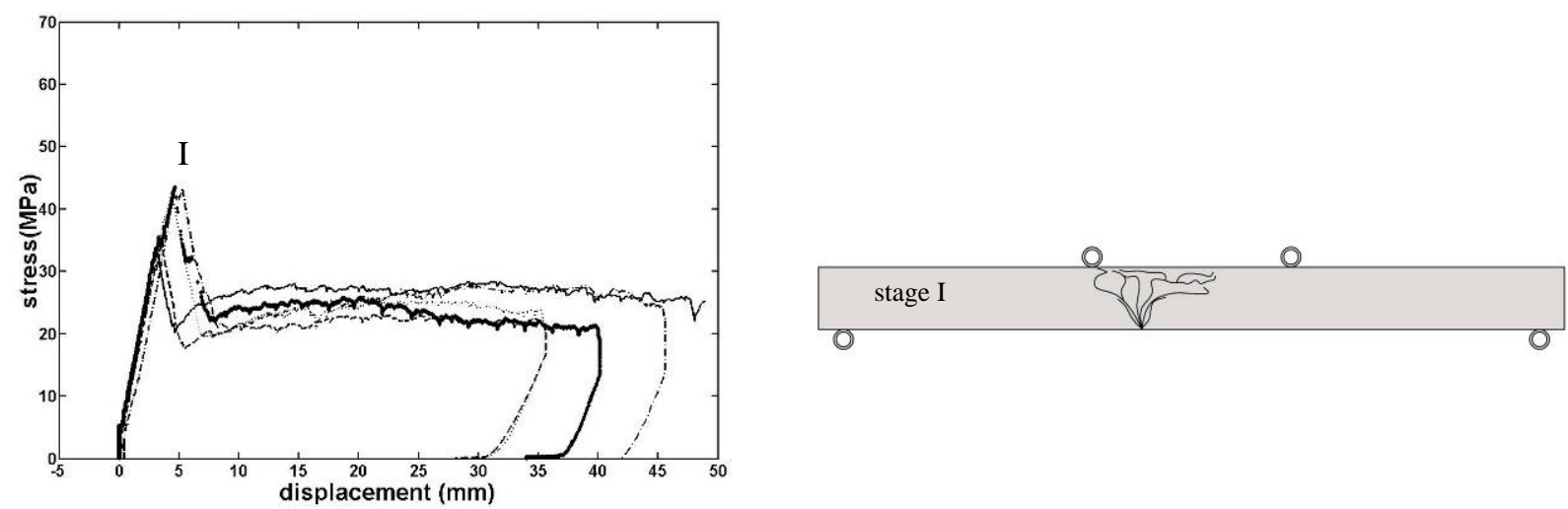

FIGURE 7 - DIAGRAM AND CRACKING SEQUENCE (STAGE I) POLYURETHANE (AR2026) SPECIMENS. 


\section{Silicone specimens}

The silicone specimens showed severe cracking with widely extended V-shaped cracks, upon initial failure (see figure 8). The reinforcement instantly debonded and, except for specimen DC895\#04, the specimens did not show any residual strength at all. Specimen DC895\#04 failed at a relatively low bending stress, which caused only a limited impact on the glass-toreinforcement adhesive bond. The reinforcement therefore did not instantly debond and the beam was only to a limited extent capable of carrying load.
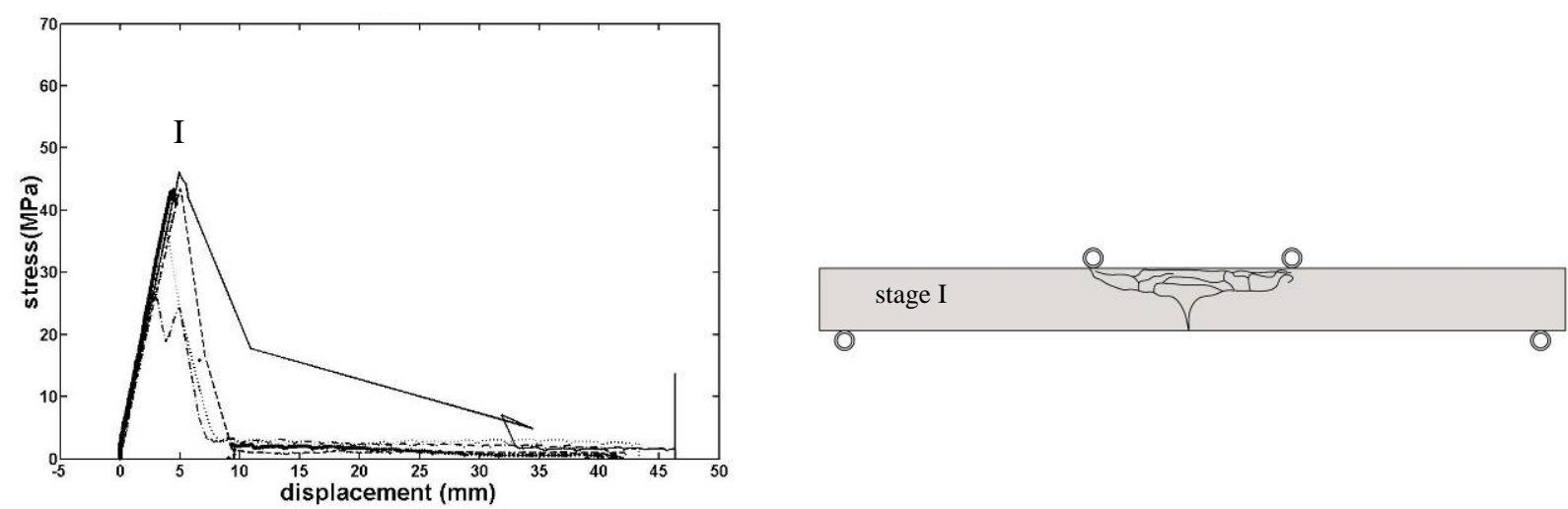

FIGURE 8 - DIAGRAM AND CRACKING SEQUENCE (STAGE I) SILICONE (DC895) SPECIMENS.

\section{DISCUSSION}

The results show a large variation in post-initial-failure behaviour for the different beam specimens.

The silicone specimens, except for beam specimen DC895\#04 (see table 2), did not show any significant remaining load-carrying capacity. The silicone bond was not able to transfer the shear forces between glass and reinforcement upon glass failure. Crack branching could therefore not be limited by any elongation of the reinforcement section. This caused severe cracking of the beam specimens upon initial glass failure and the beam specimens instantly collapsed.

The polyurethane specimens performed better than the silicone specimens. However, their remaining load-carrying capacity was still limited and their overall failure behaviour was also unsafe as they showed too little redundancy. Upon glass failure the reinforcement instantly debonded and the remaining load-carrying capacity was only generated by a limited residual friction between glass and reinforcement.

The acrylic specimens performed best. They showed a high remaining load-carrying capacity and consistent results. Only two acrylic specimens showed a remaining load-carrying capacity of only a bit less than 100\% (GB485\#01 and GB4468\#03, see table 2). This might be due to some errors at the manufacturing process. These errors, however, are hard to observe since visual inspection of the adhesive bond is not sufficient to judge the structural quality.

The acrylic GB368 adhesive performed best, since the specimens with this adhesive consistently showed remaining load-carrying capacities of $>100 \%$.

Only two epoxy specimens showed a remaining load-carrying capacity $>100 \%$ after initial failure (AR2013 \#04 and \#05, see table 2). For the other epoxy-specimens full debonding of reinforcement occurred rapidly after initial failure. The applied load did not reach the initial failure load anymore and the remaining load-carrying capacity was $<100 \%$. For the epoxy 
specimens probably not the adhesive, but the manufacturing process of the specimens was the weakest link. At the manufacturing of the epoxy specimens some difficulties were encountered. Since the glass-to-glass and glass-to-reinforcement bonding could not be executed simultaneous (due to the grey color of the epoxy adhesive) the reinforcement section had to be bonded afterwards. This caused some irregularities in adhesive thickness and an uneven distribution of adhesive over the bond area. Due to these errors at the bonding process the structural quality of the specimens was reduced.

As showed by the results of the epoxy specimens, the manufacturing process of the specimens is a critical aspect for the performance of the reinforced glass beams. Although the adhesive itself might be strong and tough enough under all conditions, the performance of the specimens is still strongly dependent on the way the adhesive has been applied. Besides their rapid curing properties, the major advantage of the UV-curing and transparent acrylic adhesives is their applicability for both glass-to-glass and glass-to-reinforcement bonding. This allows for a much better controlled bonding process, since glass-to-glass and glass-to-reinforcement bonding can be executed simultaneously. Bonding errors, as occurred for the epoxy-specimens, and other complexities are prevented. Especially for the production of large span glass beams, which are composed of several glass segments bonded together, as developed at Delft University of Technology, the rapid and simultaneous glass-to-glass and glass-to-reinforcement bonding is advantageous. Production times are limited and errors are prevented.

\section{Performance comparison of acrylic-specimens at room temperature and $60^{\circ} \mathrm{C}$}

In preceding research bending tests have been performed at room temperature on acrylic (GB368) specimens. The results of these tests have been published by Louter [3] and are briefly presented in figure 9.

The results at room temperature show comparable initial failure loads as has been observed for the bending tests at $60^{\circ} \mathrm{C}$. The remaining load-carrying capacity, however, is higher at room temperature, namely $142-184 \%$ (mean $162 \%$ ), than at $60^{\circ} \mathrm{C}$, namely $102-156 \%$ (mean $131 \%$ ). Also the final failure behaviour is significantly different. Whereas the specimens tested at room temperature show a rather explosive final failure at the compression zone without any debonding of reinforcement, the specimens tested at $60^{\circ} \mathrm{C}$ ultimately failed due to debonding of reinforcement. This difference in post-initial-failure behaviour is due to the decreased strength of the adhesive at elevated temperatures, which causes preliminary debonding of reinforcement.
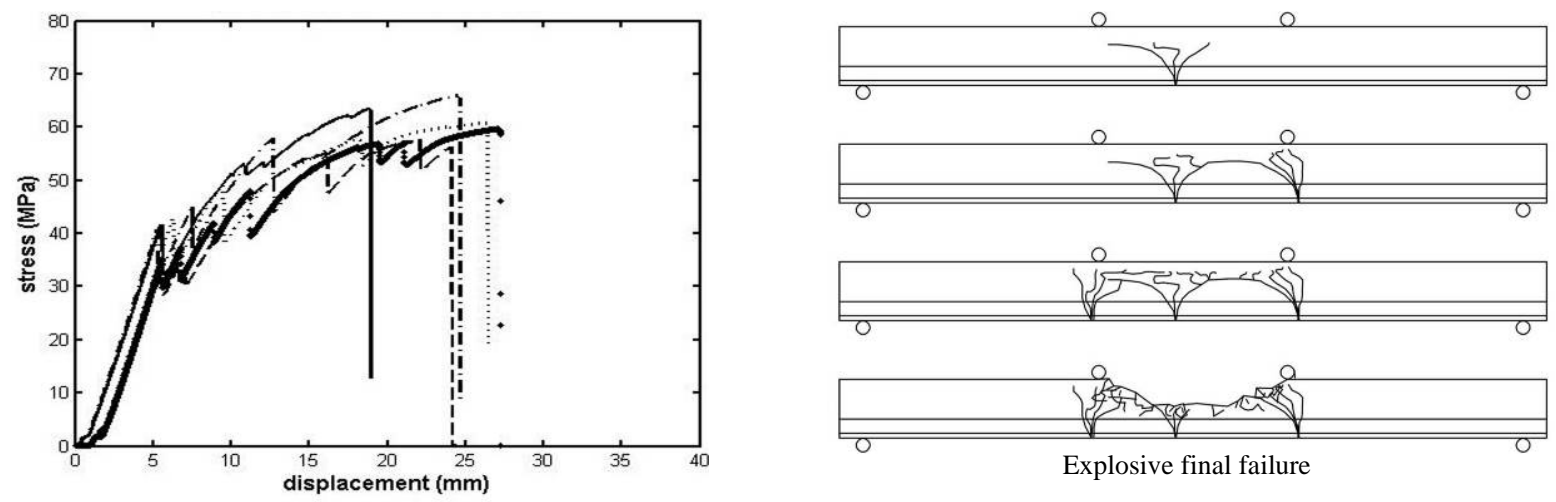

FIGURE 9 - RESULTS AT ROOM TEMPERATURE FOR ACRYLIC (GB368) BEAM SPECIMENS 


\section{CONCLUSIONS}

From the bending tests performed at $60^{\circ} \mathrm{C}$, on reinforced glass beam specimens prepared with different adhesives (2-component epoxy, 3 types of acrylic, 2-component polyurethane and 1component silicone), the following can be concluded:

- The acrylic specimens performed best, since they showed a high level of remaining loadcarrying capacity and the most consistent results. Most notably the acrylic GB368 adhesive performed well since all specimens prepared with this adhesive showed a remaining loadcarrying capacity of $>100 \%$, which is qualified as safe failure behaviour.

- The gap-filling capacities of the polyurethane and silicone adhesives offer a production advantage, since they can compensate for dimensional inaccuracies. However, due to their limited strength (at $60^{\circ} \mathrm{C}$ ) they are not suitable for bonding the reinforcement to the glass. Upon glass failure, the reinforcement will instantly debond and extensive crack branching will occur, which will significantly limit the remaining load-carrying capacity of the reinforced glass beam.

- The performance of the reinforced glass beam specimens is strongly dependent on the quality of the manufacturing process. The rapid UV-curing acrylic adhesives are advantageous for the manufacturing of reinforced glass beams, since they provide the advantage of rapid and simultaneous glass-to-glass and glass-to-reinforcement bonding, which allows for a much better controlled bonding process.

\section{ACKNOWLEDGEMENT}

The authors gratefully acknowledge the material support of DELO Industrial Adhesives, and Van Noordennegroep glass supply.

\section{REFERENCES}

[1] Veer, F.A. (2005), “10 years of Zappi research”, Proceedings of $9^{\text {th }}$ Glass Processing Days, Tampere, Finland

[2] Louter, 2007, “Adhesively bonded reinforced glass beams”, HERON Volume 52 (2007) issue 1/2 special issue: Structural glass, http://heron.tudelft.nl

[3] Louter, P.C., Veer, F.A., Hobbelman, G.J., (2007), "Reinforcing Glass, Effects of Reinforcement Geometry and Bonding Technology”, Proceedings of Glass Processing Days 2007, Tampere, Finland

[4] Delo, Industrial Adhesives, “Technical Information DELO-PHOTOBOND”, Landsberg, www.delo.de

[5] Huntsman, “Araldite 2000 series”, www.araldite.com

[6] Dow Corning, “Product information, DOW CORNING 895 Structural Glazing Sealant”, Ref. no. 10-0847I-01 